\title{
Mobile Phone Technology Engagement in EFL Classroom
}

\author{
Lili Zhang \\ School of Foreign languages and cultures \\ Beijing Wuzi University \\ Beijing, China \\ e-mail: mywritingclass@163.com
}

\begin{abstract}
Nowadays, it seems mobile phones are used everywhere by everyone, which leads to the obvious questions: Can mobile phones be used in language classes? How can mobile phone technology support the second language learning? The answers are positive: Mobile phone technology can be effectively engaged in EFL (English as a foreign language) classroom. It proves to be both reasonable in theory and feasible in practice. This paper makes an analysis of the modern English language teaching methodology and discusses how language teachers can have their students use mobile phones to best assist English language learning in the EFL classroom.
\end{abstract}

Keywords-mobile phones; EFL classes; language learning; language teaching

\section{INTRODUCTION}

These days, teachers of English as a foreign language (EFL) who want to develop successful lessons face a number of challenges, including large class sizes, traditional language teaching methodology and inadequate technological support. The big problem is unmotivated students who are so reluctant to participate in class activities. According to Harmer (2007), uncooperative and unmotivated students are a serious problem and can easily disrupt the instructional process. Usually, the routine activities with whole class lectures and drills lead to the lack of motivation, so the students take no interest or even refuse to participate. It is a most frustrating phenomenon in English language teaching.

While many teachers realize what is happening in English classes, they begin to try every means to alleviate this problem. During the process, the rapid development of high technology helps a lot. Now it is not rare that language teachers usher the computer-mediated communication, internet-based projects and telephone-aided tasks into their English classes. Indeed, hybrid tools that combine computer, internet and mobile technologies assist teachers a lot to motivate their students and therefore improve their language classes. The use of high technology is not unique. The literature is replete with all imaginative ideas on how to apply all these tools to language teaching. Among all these, the mobile phone technology engagement is worth of attention in English language teaching. The development of mobile technology, especially of the smart cell-phones, facilitates the large amount of mobile phone use in English language classes. Evidence shows it not only fulfills the major objectives of EFL lessons but also addresses a series of problems in English language teaching.

\section{Mobile Phone TeChNology AND Modern EFL TEACHING \& LEARNING}

\section{A. Current Situation of Modern English Language Teaching}

In the objectives of foreign language teaching, the achievement of students' communicative competence is greatly highlighted. An analysis of English language teaching methodology reveals that achieving communicative competence in a second language involves not only knowing the grammatical rules of a language but also knowing when, where, and with them to use the language in a contextually appropriate way (Ellis 1994; Hymes 1971; Richards 1985). As many teachers know, in EFL classes, they should pay much attention to students' skill in how to use English in communicative situations, rather than mere knowledge of English grammar and vocabulary. According to Brown (1994), communicative language teaching allows learners to practice English as it is actually used in a speech community and equips them with the language skills they will need when they leave the classroom for the real world.

However, the principles of communicative language teaching are not always easy to put into practice in classes. Due to the large class size, some productive activities involving students' communicative skills seem to be demanding, time-consuming and less controllable. The low-efficiency makes teachers tend to favor receptive activities involving reading and listening. The result is teacher-centered language instruction which has been commonly considered as inefficient and ineffective language teaching method ever. Another fact is that students in most cases feel too shy or embarrassed to speak in class or to show in front of audience, especially in English. This performance anxiety students have in the language learning process does not support the development of communicative competence in English language classes. Since the communicative approach is of Western origin, it is best suited for the interactive classrooms of Western cultures, where communicative activities are more common (Harmer 2007). Therefore, teachers may feel very disappointed and frustrated when they expect the ideal effect of this teaching method in a country like China where it is considered as a virtue for students to listen, to obey in most learning situations. Under all these circumstances, any technology support for the development of communicative competence is essential to EFL classes. 


\section{B. Theoretical Background of Mobile-assisted English Language Learning}

There are several pedagogical theories supporting the using of mobile phones in the second language classroom. The situated learning theory states that learning is more likely to take place when information is contextually relevant and can be put to immediate use (Lave and Wenger 1991). Mobile phones are social tools that can facilitate authentic and relevant communication and collaboration among learners. For example, English language learners can use mobile phone technology to access relevant vocabulary and expressions while at a bank opening an account, or to discuss weekend plans with an English-speaking friend. According to principles in applied linguistics, any tool that can increase students' access to the language will contribute greatly to their progress (Reinders 2010). Since mobile phones are part of students' everyday routines, they help them minimize the distance between the classroom and the real outside world, and improve the efficiency of language learning.

Another appealing backdrop behind using of mobile phones in the classroom is the development of self-regulated learning in modern web-based learning environments. With help of mobile phone technology, the students can give control over their own learning. During the wide range of daily social activities where mobile phones are most likely to be used, students control the medium, and teachers, by elaborating how to use the medium for the best, provide a blueprint for self-regulated learning. It serves as supportive evidence for autonomous learning theory.

\section{Practical Feasibility of Application of Mobile Phone Technology in EFL Classes}

It proves quite feasible to use mobile phone technology in EFL classes. These days it seems mobile phones are used everywhere by everyone. Mobile phones are relatively cheap and increasingly powerful, especially when more and more smart mobile phones become popular. They are so portable, convenient and smart that learners are used to working with them, often more so than with computers. Thornton and Houser (2003) report that young Japanese learners prefer to use mobile phones for many activities, from emailing to reading books to shopping. Research on the use of mobile phones for the delivery of vocabulary materials to English learners in China shows that students enjoy using their phones because of easy access to materials and the ability to practice anytime and anywhere; in addition, some students like the screen size limitations, which make the amount of content more manageable than that of other teaching materials (Chen, Hsieh, and Kinshuk 2008).

There is an enormous range of phone makes and models, and the technology is always advancing. The teacher needs to take stock of the resources that he has available. Using mobile phone technology is adding value to the language class. To make it work, the teacher need to make a plan beforehand when using mobile phones in EFL classes. A specific teaching objective should be identified and then a mobile phone activity around that is structured. Full preparation by teachers is necessary before asking students to pull out their mobile phones in class, which add the feasibility to the mobile-assisted language teaching and learning.

\section{Practical Activities With Mobile PhONES IN EFL Classes}

With the rapid development of modern mobile technology, more and more features and functions are found in mobile phones, which sparks more ideas for using them in the language classroom. The following are some practical engagement of mobile phone technology in EFL classes. They offer great evidence that mobile phones can be a very efficient and effective tool of communicative language teaching and learning.

\section{A. Note-taking and Memory}

Most mobile phones have a feature that allows them to take notes. Students can use this function to take notes on the English both what they learn in class and what they read or hear outside class. The teacher can ask students to hunt for specific language forms and collect them in the phone. It can break the boundary between class time and daily activities and lead students to learn continuously even when a classroom lesson is over. What's more, nearly all phones have memory for graphics, photos and audios that you can use to download listening and reading materials for students who can in turn transfer them to their phones or other media. Many books are now published in mobile-friendly formats. Students can use the voice recorder to take notes about the book while they are reading. The books, along with students' reflections, can then be discussed during the class.

\section{B. Photographing and Recording}

One of the easiest ways to use a mobile phone for learning is to record samples of the target language by photographing and recording. Students can take pictures of English text by using the camera feature on their mobile phones. They can also collect language samples from TV or radio and make the voice memo. Then they can make a language data base, upload the pictures or audios and share with classmates while practicing the language in groups. One excellent activity in this respect is producing video drama projects with mobile phones. Students are asked to design a project-based video task which combines drama, technology and communicative language teaching, motivates students because they enjoy recording with their mobile phones, and breaks the monotony of traditional class teaching and is enjoyable and stimulating. In the drama project, students need to write English scripts, engage in peer correction and design and produce the video in English, so it is an excellent way to get students to use different communicative functions in English and reinforce their language skills.

\section{Text Messaging}

A study by Thornton and Houser (2003) shows that Short Message Service (SMS) text messages can be used to 
send out vocabulary items at spaced intervals, thus increasing student retention. For example, you could text the words covered in class to encourage students to review them outside the school. By sending out the words many times, you increase the chances that students will remember them eventually. On the other side, text messaging feature of mobile phones can also be used to motivate students' writing interest and improve their English writing skills. If one considers writing as any form of textual communication, it becomes clear that students actually write a lot. One effective activity is circular writing, where students create a story together by contributing one text message at a time. Each student writes a sentence or two and then sends this on to the next student, who adds another message, and so on until the story is complete. During the process, students are encouraged to grasp the language skill and improve their communicative competence in English.

\section{Social Networking}

No report on mobile writing would be complete without mention of Weibo, the popular microblogging service in China now. Microblogging involves sending short messages from a computer or a mobile phone. Teachers can use Weibo for a wide range of English assignments, such as asking students to report on their daily activities. Students can follow each other's updates and respond to them. Like Weibo, Weixin, Feixin, QQ, MSN are enormously popular social networking tools that allow groups of friends to talk, send messages, share pictures, and generally interact online in a number of ways. Most of the interaction takes place in writing and speaking, so simply asking students to use English instead of their native language produces a great deal of communicative practice in English. In the meantime, teachers can actively use such tools to keep in touch with students or to organize activities online. It proves to be an efficient and enjoyable way for both teachers and learners.

\section{E. E-portfolio}

Most learning inevitably takes place outside the classroom. Students are encouraged to reflect about their language acquisition any time and keep a formal journal or portfolio for the reflections. Mobile phones, by virtue of portability, can help. Students can document their learning process by using the note-taking and voice memo features and set up the formal e-portfolio. Teachers could also use portfolio assessment to give credit for work done outside the classroom, which is possible with a mobile phone. In addition, students can as well use the calendar feature or other productivity tool available on mobile phones to set goals, deadlines, for assignments and reminders to rehearse material covered in class (Reinders 2010).

\section{Potential PROBLEMS AND SOLUTIONS}

Following are some potential problems associated with using mobile phones in EFL classes, along with some possible solutions and suggestions.

\section{CONCLUSION}

\section{A. Cost Problem}

It is safe to say that of all the teaching technologies available to teachers, mobile phones are the most widespread, but we still cannot guarantee all students in all classes will have access to mobile phone technology. To some degree, a financial burden is placed on students and their parents when they are required to use the phones as a learning tool in class. Activities such as texting, going online, making calls cost money. Not every student has an unlimited texting or calling plan, so the charges could be high. To address this problem, transferring text messages to a computer is one way to avoid texting charges. For some group activities, students can also share a mobile phone in one team, which put down the general cost. Another choice is to send text messages via free-of-charge service through internet, such as Feixin or Weixin. As long as students can land available Wifi, the cost problem is then alleviated. In the same spirit, some website such as www.textmefree.com can also offer free texting, which proves to be cost-efficient.

\section{B. Efficiency Problem}

The portability is the most sparkling advantage of mobile phones in EFL classes, but compared with computers, they still present some disappointing characters, such as smaller memory size, lower speed, limited functions, and less-controllability. All these disadvantages may lead to the low efficiency of language classes. In addition, phones can be disruptive. For example, it would be counterproductive if they ring in class in the middle of a silent reading activity. In that case, teacher should have clear tasks for students to work with, and some ground rules are needed. Another fact is that the use of mobile phones as a language teaching tool may increase teachers' workload. It is always a question of how to deal with the extra communication that use of phone generates. What happens if all of your students start texting you? So teachers need to set boundaries and make a clear assignment schedule to students. In general, the efficiency problem makes mobile phones only an assisting teaching resource in EFL classrooms.

\section{Privacy Problem}

Mobile phones are privately-owned and with much privacy involved, so when they are used as a common teaching and learning tool in class, it may cause some problem. Some students may be reluctant to share private information with others, some may refuse to share the phones in group activities, and some may use mobile phones to violate others' privacy by taking photos, making video recordings, or even spread some private information through internet. Therefore, it is very important to consider issues of privacy before using mobile phones in class. Teachers need to explain to students what the teaching objectives are and find out if they have any concerns about using their phone for learning activities. At the same time, clear rules need to be nailed down about when and how 
mobile phones can be used to avoid inappropriate purposes and behaviors.

The mobile phone technology engagement is an effective option for the language teachers in EFL classes. With the development of modern mobile technology and current situation of English language teaching, introducing mobile phones into the EFL classroom is highly recommended because they are inherently convenient and motivating, and they offer great potential for student interaction and practice with authentic communicative language functions. Like applying any other new technological teaching tools, using mobile phones in EFL classes is associated with a series of problems, including that of cost, efficiency and privacy. These problems can be lessened with the great efforts from both teachers and students. Dealing with the challenges of using mobile phones may seem daunting, but more and more teachers have found it to be a worthwhile investment of their time and a welcome addition to their EFL classes.

\section{REFERENCES}

[1] H. D. Brown, Principles of Language Learning and teaching. Englewood Cliffs, NJ: Prentice Hall, 1994.

[2] N. S. Chen, S. W. Hsieh, and Kinshuk, "Effects of Short-term Memory and Content Representation Type on Mobile Language Learning," Language Learning and Technology 12 (3), 2008, pp.93-113.

[3] R. Ellis, The Study of Second Language Acquisition, Oxford: Oxford University Press, 1994.

[4] J. Harmer, The Practice of English Language Teaching, Harlow, England: Longman, 2007.

[5] H. Hymes, On Communicative Competence, Philadelphia: University of Pennsylvania Press, 1971.

[6] J. Lave and E. Wenger, Situated Learning: Legitimate Peripheral Participation, Cambridge: Cambridge University Press, 1991.

[7] H. Reinders, "Twenty Ideas for Using Mobile Phones in the Language Classroom," English Teaching Forum, 2010(3), PP. 21-23.

[8] J. Richard, J. "Conversational Competence through Role Play Activities," RELC Journal 16 (1), 1985, PP. 82-100.

[9] P. Thornton and C. Houser, Using Mobile Web and Video Phones in English Language Teaching: Projects with Japanese College Students, Hong Kong: Hong Kong Polytechnic University, 2003. 